\title{
METALLURGICAL ASPECTS OF RELIABILITY FOR SMALL NITRIDED PARTB
}

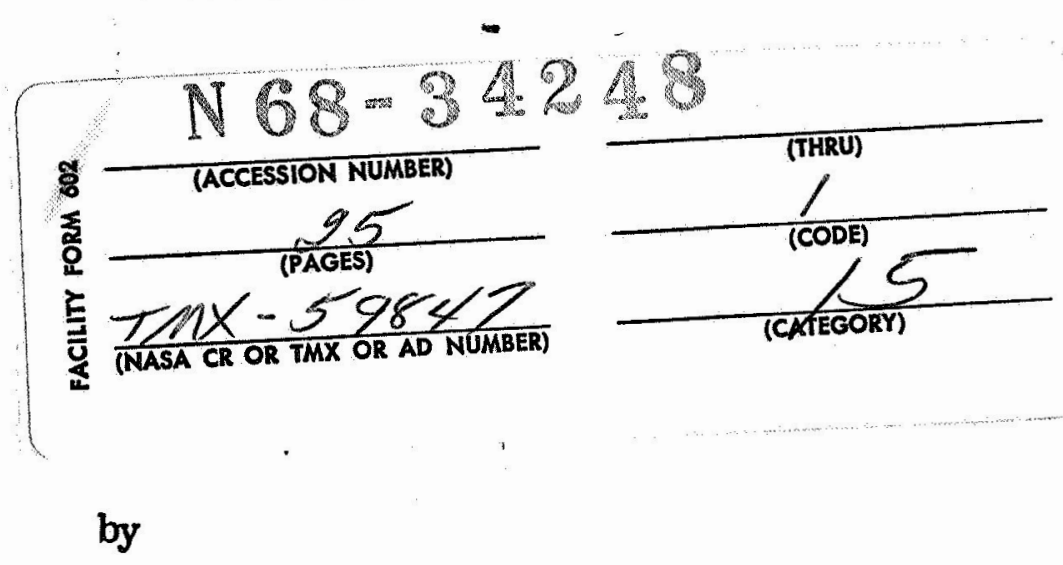

Alfred J. Babecki

Materials R\&D Branch

Systems Division

Goddard Space Flight Center

Greenbelt, Maryland 


\section{ABSTRACT}

Many spacecraft experiments and systems employ drive systems which contain gear trains, slides, rachets, and similar components subject to sliding wear. In order to inhibit or mitigate the wear, some manufncturora omploy surfaco hardoning procossos, including nitriding. Cases of three such applications are reviewed: One involved rachets made of Nitralloy $135 \mathrm{M}$ on a spectrometer grating drive. These rachets suffered excessive embrittlement of the very small (10 mil height) rachet teeth. Another case involved Type 416 stainless steel gears in a small motor gear train. These were nitrided by a proprietary process and suffered flaking of the nitriding and chipping of the gear teeth during testing. A third case involved a pinion gear on an infrared scanner which also was made of Nitralloy $135 \mathrm{M}$ and nitrided to increase its surface hardness. This gear was subject to flaking of the nitrided case and also breakage of the teeth.

In all of these cases, metallographic examinations and microhardness measurements were made. These disclosed that the case hardening operation resulted in an excessively deep hardened zone which rendered the hardened parts extremely brittle.

Discussion is made of the principles of case hardening, of the internal stresses that are introduced, and of the difficulties of applying the conventional process for large piece parts to the very small piece parts of many spacecraft systems. Alternate solutions to the wear problem of aliding mechanisms are presented. 
TIIE QUESTION OF rotating or sliding hardware for operation in space is one that always causes many spacecraft engineers a lot of worry, and rightly so. For the malfunction of a drive system, a shutter slide, a bearing, an electrical contact, or similar critical moving component during operation in orbit can result in the loss of either an experiment or a spacecraft valued at many thousands or millions of dollars.

It has been well established that the early demise of the Nimbus A spacecraft was due to failure of a bearing in the drive motor of the solar: array. Other spacecraft have experienced failures in tape recorder bearings. And during the testing phase, at least, other spacecraft systems and subsystems have suffered failures of slides, gear drives, and rachet-pawl, assemblies.

Many techniques are employed to prevent, or attempt to prevent, failures of these units due to friction buildup or actual cold bonding. These include hermetic sealing, liquid or solid lubricants, reservoirs and labyrinth seals, dissimilar metal couples, and metal surface treatments.

Among the last-named techniques are the surfacehardening processes for steels, carburizing and nitriding. Both of these processes have been used for many years in surface hardening gears in the automotive and railroad industries. These processes also are being used to some extent in spacecraft applications, such as spur and pinion gears in motor gearheads.

This paper will describe three spacecraft applications in unmanned scientific satellites which involved nitrided components in drive systems. The nitrided components in these systems suffered failures during testing and are typical of other similar failures. Metallographic examination results to be presented will reveal deficiencies in the materials that should be guarded against, as well as nitriding process precautions to be observed to increase the reliabllity of amall parts thus treated.

\section{WHAT IS NITRIDING}

DESCRIPTION OF PROCESS - Nitriding is a process to increase the hardness of a ferrous alloy by the " diffusion of nitrogen into the alloy to form hard nitrides, mainly iron nitrides. Since diffusion must proceed from the external surfaces inwardly, it is a process used to increase the surface hardness of the part. The depth to which the nitrogen will diffuse is dependent on both the length of time and the temperature

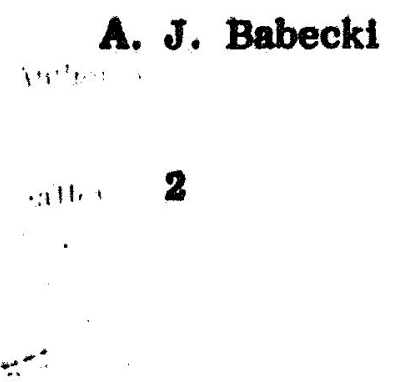


of cxposure of the surface to the nitrogenous material. Other factors, such as composition of the alloy and of the nitrogen-producing medium, also influence the rate of the process.

Nitriding can be performed in either a liquid medium or in a gas atmosphere, at temperatures in the range of 950 to $1050 \mathrm{~F}$. Many proprietary modifications have been made to the standard nitriding media which are designed to speed up the process, increase the variety of steels which can be treated, or effect other improvements. In general, however, the processes introduce a nitrogen gradient into the steel which may reach as high as $0.20-0.30 \%$ at the surface.

The diffusing nitrogen reacts with the elements in the steel to form one or more of several different nitrides, such as $\mathrm{Fe}_{2} \mathrm{~N}, \mathrm{Fe}_{3} \mathrm{~N}, \mathrm{Al} \mathrm{N}$, and $\mathrm{Cr} \mathrm{N}$, in addition to forming complex compounds with $\mathrm{Fe}_{3} \mathrm{C}$. The introduction of the nitrogen into the atomic lattice of the iron, or other element, changes the dimensions of the lattice and tends to expand it. The greater the quantity of nitrogen introduced, the greater is the expansion effect.

BENEFICIAL EFFECTS OF NITRIDING - The expansion of the nitrided layer on a steel part is resisted by the unnitrided metal beneath the surface. Accordingly, the stress pattern on such a processed part varies from a maximum compression on the external surface, through zero at the interface between the nitrided and unnitrided metal, to a maximum tension immediately beyond this interface, to a reduced tensile value within the core of the material, as shown in Figure 1.

There are certain advantages to having a compressive layer on the surface of a metal part, especially if it is subjected to varying stresses. One important benefit is that the fatigue life is materially improved by virtue of the fact that the compressive stresses in the surface cancel out a portion, or all, of the applied service stresses, depending on their relative magnitudes.

This benefit is also derived by such other surface modification techniques as shot peening (glass bead peening), carburizing, planishing, and surface induction hardening.

Other advantages to be gained from the nitriding process, which may in part be the result of the compressive surface stresses, are increased wear resis-

. A. J. Babecki

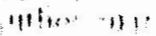
tance and anti-galling properties, improved corrosion resistance, enhanced resistance to elovated temperam ture softening. 
Probably the most familiar reason for the use of nitriding is that of increasing the surface hardness. A high hardness on a steel surface improves the wear resistance in a manner similar to that of the high compressive stress in that it restricts the depth to which the mating surface may penetrate or deflect it.

HARMFUL EFFECTS OF NITRIDING - Some of the same properties which are termed beneficial above can also produce harmful effects which may compromise the reliability of the nitrided part. The high hardness of the nitride layer also has rather low duc-: tibility and may be subject to cracking if the nitrided part is mishandled or deflected excessively. Such sharp cracks may subsequently serve as stress concentrators to initiate brittle failure at low temperaItures where the core material has reduced toughness, or may serve to initiate fatigue cracks.

Another precaution to be observed is that of distortion. The compressive forces introduced into the surface by the nitriding process are the result of a volume increase. If this increase is not balanced symmetrically, there may be a resulting distortion or dimensional change.

The magnitude of the permanent set in the core and case is affected by the yield strength of the material and by the amount and nature of the nitrides formed. Accordingly, growth and distortion in nitrided parts are governed largely by composition, tempering temperature, time and temperature of nitriding, relative thickness of case and core, and shape of the part.

Figure 2 illustrates the growth that occurs in a nitriding alloy hollow cylinder as a function of wall thickness. In another case, the bore diameter of a 12-in.-dia. spur gear decreased by 0.001 in. while the OD increased by 0.004 in.

\section{PROBLEMS NITRIDING SMALL PARTS}

CASE-TO-CORE RATIO - The advantages of nitriding apply only to parts having substantial thickness. The total compressive load on the case must be balanced by the total tensile load on the core. The larger the area of the core, the lower will be the unit stress in the core needed to hold the nitride layer in compression. Conversely, the smaller the cross section of the core, the higher the tensile stress in it to balance the force exerted by the case. As a result of this higher tensile stress, the applied stress required to produce fatigue fallure or spalling will be smaller. 
Since the core stress varies with the ratio of core-tocase area, nitriding will be of negligible advantage for stressed members if the core is too light.

In spacecraft applications, the parts which are nitrided are given this treatment to maintain a low coefficient of friction and to inhibit wear. The actual parts so treated may vary from gears several inches in diameter to some that are of the order of $0.25 \mathrm{in}$. in diameter. Therefore; the core-to-case ratio required in each instance may vary considerably.

Other factors which may influence the optimum core-to-case ratio in small spacecraft components are the speed of rotation or sliding, the load applied, the vibrational spectrum and magnitude imposed by the launch vehicle, and the type and length of operation. Some motor gearheads are required to operate at 2000-5000 rpm continuously for a year or longer; others may operate only intermittently over a much shorter period.

SIZE CONSIDERATIONS - In general, it can be said that the spacecraft hardware which is subjected to nitriding processes is of a much smaller size than that which is commonly nitrided in the automotive, railroad, or machinery industries. For that reason it has been a problem to get heat treating vendors who are immediately conscious of the size effects.

The production of small nitrided parts for space hardware does not constitute a large-volume business. Therefore, there are not too many heat treaters who welcome this business when not especially set up to do small precision parts. As a result, much of these parts have been processed by conventional large-piece techniques, perhaps with slight modifications.

As an outcome of this lack of consideration for the size of the parts, much of the commercially nitrided hardware has been returned from the heat treating company in a highly unreliable condition. Several conditions in these parts, while they would have been acceptable in large components, were definitely degrading of the quality of the smaller ones. These con-, ditions included large case-to-core ratios, surface defects and tooling marks, sharp external corners, extremely brittle white nitride surface layers, and metallurgical deficiencies in the alloys.

The following paragraphs will describe three separate spacecraft applications which experienced fallures in nitrided components because of one or more of these conditions. All of these fallures occurred A. J. Babeckl
Anl 
during assembly or testing. Of courise, it is impossible to know for certain if any of the spacecraft fallures in orbit can be attributed to a similar problem.

\section{DESCRIPTION OF FAILURES}

IR SCANNER DRIVE GEAR - The IR scanner was: a hermetically-sealed unit under one atmosphere of argon and with a motor that operated continuously at $8,000 \mathrm{rpm}$. It had a small (0.354 in.-dia.) output pinion gear made of nitrided Nitralloy $135 \mathrm{M}$ which engaged a much larger gear of Type 303 stainless steel. The gears and bearings were lubricated with Mil-L-7870 oil (Esso aviation instrument oil).

After vibration testing, four of the scanner drives were found to have badly chipped and broken pinion gears. Inspection of several other units with less testing time disclosed that they, also, had chipped pinion gear teeth-some more so than others.

Figure 3 pictures one of the pinion gears exhibiting a broken tooth. The small size of the gear should be evident from the photo, but the size of the gear teeth is even more surprising when stated as measuring $0.025^{\prime \prime}$ in height and $0.017^{\prime \prime}$ in width at the pitch circle. The drawing for this gear called for a nitrided case depth of 3-6 mils, but failed to specify the criterion for defining the case depth. Technically, the depth of the case is regarded as the depth to which some change in composition or properties has been effected by the surface hardening process.

In addition to the broken tooth, the gear exhibited much chipping of the nitrided layer, Figure 4. Fractographic analysis of the fracture surfaces of the broken tooth indicated that it was not a fatigue failure, but a sudden cleavage failure, such as might happen under impact loading.

The gear was sectioned to provide both longitudinal and transverse specimens for metallographic examination. Figure 5 presents the transverse cross section of a tooth showing the chipping of the case outer layers at the external edge of the tooth apex face.

Microhardness measurements disclosed that the chipping layer represented hardness in excess of $\mathbf{R}_{\mathbf{C}} \mathbf{7 0}$ and that this hardness persisted to a depth of $2.5 \mathrm{mils}$ The total case depth, measured to a hardness of $R_{c^{50}}$ and representing brittle material, was 7 mils from the tooth apex face. Measured to the point of unaf fected base material, the case depth was 15 mils 
In other words, the outer third of each tooth was in a highly-stressed extremely-brittle and vulnerable condition. In fact, metallographic examination of the broken tooth indicated that the break had occurred through the $\mathrm{R}_{\mathrm{C}} \mathbf{5 0}$ hardness zone. In this case, therefore, the case-to-core ratio was excessive, and the surface hardness and internal stress also was excessive in that they both promoted cracking and chipping of this outermost layer.

In another metallurgical respect the Nitralloy $135 \mathrm{M}$ was of questionable quality; it exhibited a large number of large aluminum oxide inclusions which were angular and which could serve as stress concentrators when located near the surface to cause failure of the case or of a tooth. Figure 6 depicts one of these inclusions in a transverse view.

In this application it was evident that the case depth was too great; the hardness, and therefore the internal stress, was excessive; sharp external corners were prevalent at which the compressed surface was under orthogonal tension that tended to spall it off; the specifications covering the alloy and the nitriding process were not explicit and did not call for good quality control.

Two alternative recommendations were made. These included the use of a thinner nitrided case of lower hardness formed only over the tooth wear surfaces, or a change to a through-hardening tough steel heat treated to $R_{C}$ 50-55 and glass-bead peened.

SOLAR ARRAYY DRIVE GEARS - The drive system for rotating the solar cell platforms on a spacecraft was not hermetically sealed. It included a motor and gearhead box in which the six spur gear and pinion sets were machined from Type 41.6 stainless steel and nitrided by a proprietary liquid process. Failure of a drive unit necessitated disassembly for examination, at which time it was learned that the gears in the gear train exhibited evidence of spalling or chipping of the nitrided surfaces.

Although the degraded condition of the gears were not directly responsible for the drive failure, a metallurgical examination was performed to ascertain the cause for the defective surface hardening.

Figure 7 pictures a pinion gear showing a typical condition which existed on practically all of the gears in the train. Large areas of flaking of the nitrided case had occurred both in and out of the wear track. In fact, some flaking had also developed on the gear shafte. 
In the metallographic examination of the gears it was learned that the Type 416 stainless steel exhibited large quantities of ferrite in the microstructure and that this relatively soft microconstituent was distributed in the form of bands oriented parallel to the axis of the gear teeth. It was learned that the gears had been machined from bar stock of the stainless steel such that the axis of the teeth were parallel to the working direction of the bar stock. This accounted for the banded structure of the ferrite.

However, a properly heat treated Type 416 stainless steel possesses less than $5 \%$ of the ferrite constituent, and this in a random distribution. The gears in this instance had $25-30 \%$ of the soft phase. Figure 8 presents a longitudinal plane through a spur gear to show the banded structure of the ferrite and how this low nitride-forming phase tends to serve as a sharp demarcation between the nitrided case and the core material. Much of the flaking noted followed along these ferrite bands, Figure 9.

Another metallurgical feature which was considered undesirable was the high content of stringer-type inclusions in the alloy. Type 416 has sulfur deliberately added to improve its machineability. In the working of the metal, these insoluble inclusions become elongated in the direction of working, which also happens to be the tooth axis direction in these gears. Accordingly, these inclusions can become 10cated at the root radius of a tooth and can serve to initiate a fatigue failure under cyclic stresses. Such failures have occurred in spacecraft gears machined from leaded phosphor bronze.

In the solar drive gears, the ferrite banding undoubtedly restricted the development of an adherent nitride layer, in addition to serving as a soft substrate and also an internal flaw in the material which possesses much lower mechanical properties than a tempered mortensitic structure of a proper Type 416 stainless steel.?

SPECTROMETER GRATING DRIVE RACHET A drive system for a spectrometer grating on an observatory spacecraft included a pair of rachet wheels and associated pawls. Originally the wheels were machined from C1018 plain carbon steel and were carburized with a 5 to 10 mil thick case. During operation, the rachet wheels suffered extensive tooth 
breakage. In an attempt to correct the problem, the contractor changed the rachet material to Nitralloy $135 \mathrm{M}$ with nitriding by the Floe process to a depth of 2-4 mils, but with no criterion specified for determining case depth.

Although designed for a life of at least two million actuations, the rachet wheels developed extensive tooth breakage within the first few thousand actuations. Indeed, some of the wheels were found to have extensive tooth damage on receipt from the last processor. It turned out that after being machined by one vendor, the wheels went to a heat treater for nitriding, then to an electroplater for a plating of gold, and finally to another processor for application of a $\mathrm{MoS}_{2}$ coating.

The contractor believed that wear or cold bonding between the sliding metal surfaces would be a problem in the vacuum of space; hence, the hardened surface, the gold plating, and finally the $\mathrm{MoS}_{2}$ coating. What was not considered was the fact that the chisel edge of the hard C1095 steel pawl would quickly remove the $\mathrm{MOS}_{2}$ and gold.

A failed motor was disassembled, and the two rachet wheels were found to have extensive tooth damage. Figure 10 pictures a straight-on view of the rachet wheel and a close-up view of some of the damaged teeth. With the diameter of the wheel being only about $1 / 4^{\prime \prime}$, one can imagine the small size of the teeth. As a matter of fact, the teeth were set at a $45^{\circ}$ angle and had a slant height of only $12 \mathrm{mils}$.

There was a problem with the pawls also, but since they were not nitrided they will not be discussed.

With the aid of a microscope, it was learned that slight pressure on the unbroken portions of the teeth with a sharp instrument caused tooth fragmentation, indicating the fragility of their condition. The appearance of the broken surfaces definitely was of a brittle nature.

Two rachet wheels were examined metallographically, and both gave similar results. Figure 11 shows broken and non-broken teeth in cross section and in the chemically-etched condition. The dark-etched region indicates the area of maximum nitrided hardness,

\section{A. J. Babeck1}

A. 
and it is seen to occupy most of the tooth depth. Microhardness measurements revealed that the typical tooth had a hardness of $65 \mathrm{R}_{\mathrm{C}}$ or more to a depth of 7 mils, representing more than half the height of the entire tooth. Actually, the entire tooth had been hardened by the nitriding process, as evidenced by a hardness of $R_{C} 50$ at the maximum depth of the tooth, whereas the core hardness of the wheel was $R_{C} 30$.

The examination disclosed that almost the entire cross section of the rachet teeth was embrittled by the nitriding, instead of having received only a hard surface layer. Concomitantly, the high internal compressive stresses that accompanied the nitriding tended to pop off the teeth because of the acute external angle they present. Therefore, the additional stresses Imposed by subsequent service, or handling, precipitated the failures.

It was recommended that surface hardening techniques not be used on such small components because of the difficulty in maintaining the required control of the process and in performing adequate inspection. As a substitute for the nitrided Nitralloy, a throughhardening but tough steel was recommended, heat treated to a hardness of $50-55 R_{C}$ to match the hardness of the pawls.

\section{CONCLUSIONS}

Although the nitriding processes are fairly well established and commonly used to surface harden relatively large steel components, their use on the type of miniature articles described here is more critical and demands tighter controls. On large items, a rather wide variation in case thicknesses normally: can be easily tolerated; on these almost microscopic: gears, rachet wheels, and similar spacecraft hardware, such is not the case.

i With the greater control and finesse demanded in the nitriding of miniature components, it is noted that for high reliability the quality control techniques in some cases need improvement. - One reason for this. situation is that much of the heat treatment of these small parts is conducted by shops which are accustomed to working with the larger pieces of hardware. And these shops may not be in the habit of running through sample pieces and performing a metallographic examination on them to ascertain the quality of their work. Indeed, many of these shops do not have adequate laboratory equipment or personnel to perform such an evaluation.

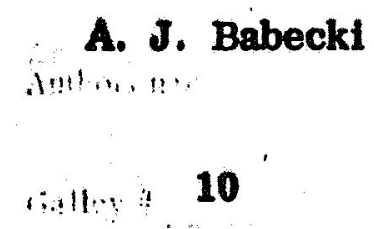


There are many instances of good quality initriding on small spacecraft components, which provide evidence that it can be done when all - people concerned realize the potential problems and take measures to avoid them.

In view of the foregoing discussion, it should be emphasized that before it is decided to resort to n1triding the surface of such small parts the following points should be considered:

1. Is an extremely high surface hardness $\left(R_{c} 60\right.$ and harder) necessary? Would a lower surface hardness achievable by conventional quench and temper or aging treatments be adequate?

2. Eliminate sharp external corners and thin sections. If this is not possible, stop off such vulnerable sections so that they do not receive the nitriding.

3. Make certain that the base material is in a good metallurgical condition.

4. Choose a heat treater who has good experience in nitriding small components. Provide detailed specifications that call out the criterion for measuring case depth, e.g. hardness value of $R_{C} 50$. Include samples for metallographic examination.

Finally, if at all possible, obtain the services of a qualified metallurgist who can review the design and material of the component, write the heat treatment specification, monitor the process, and examine the fintshed product.

\section{A. J. Babecki}




\section{FIGURE CAPTIONS}

Fig. 1 - Schematic of stress distribution in a nitrided surface.

Fig. 2 - Growth in 2-3/4 in.-dia. hollow oylinders as a function of wall thickness.

Fig. 3 - Output pinion gear of scanner drive with broken tooth (arrow).

Fig. 4 - Magnified view of chipped nitride layer on teeth of scanner drive gear.

Fig. 5 - Cross section of scanner drive gear etched to reveal chipped brittle nitride layer. White outer layer is nickel plating to preserve edge during polishing. Nital-picral etch.

Fig. 6 - Large $\mathrm{Al}_{2} \mathrm{O}_{3}$ inclusion in cross section of scanner drive gear near surface. Cracking of outer layer of nitrided zone also evident.

Fig. 7 - Spalling of nitrided case on pinion gear of solar array drive.

Fig. 8-Microstructure of solar array drive spur gear in longitudinal cross section. Ferrite banding are light areas. Vilellas etch.

Fig. 9 - Region of chipped nitrided layer following sharp boundary between case and core on solar array drive spur gear. Nital etch.

Fig. 10 - Rachet wheel from spectrometer grading . A. J. Babeck1 drive in full view (left) and in close-up (right). Fragmented teeth are evident. 
Fig. 11 - Cross sections of broken (left) and nonbroken (right) rachet teeth at two magnifications.

Heavy white layer is nickel plating to preserve edge during polishing. Nital etch.

A. J. Babecki in: r...; 


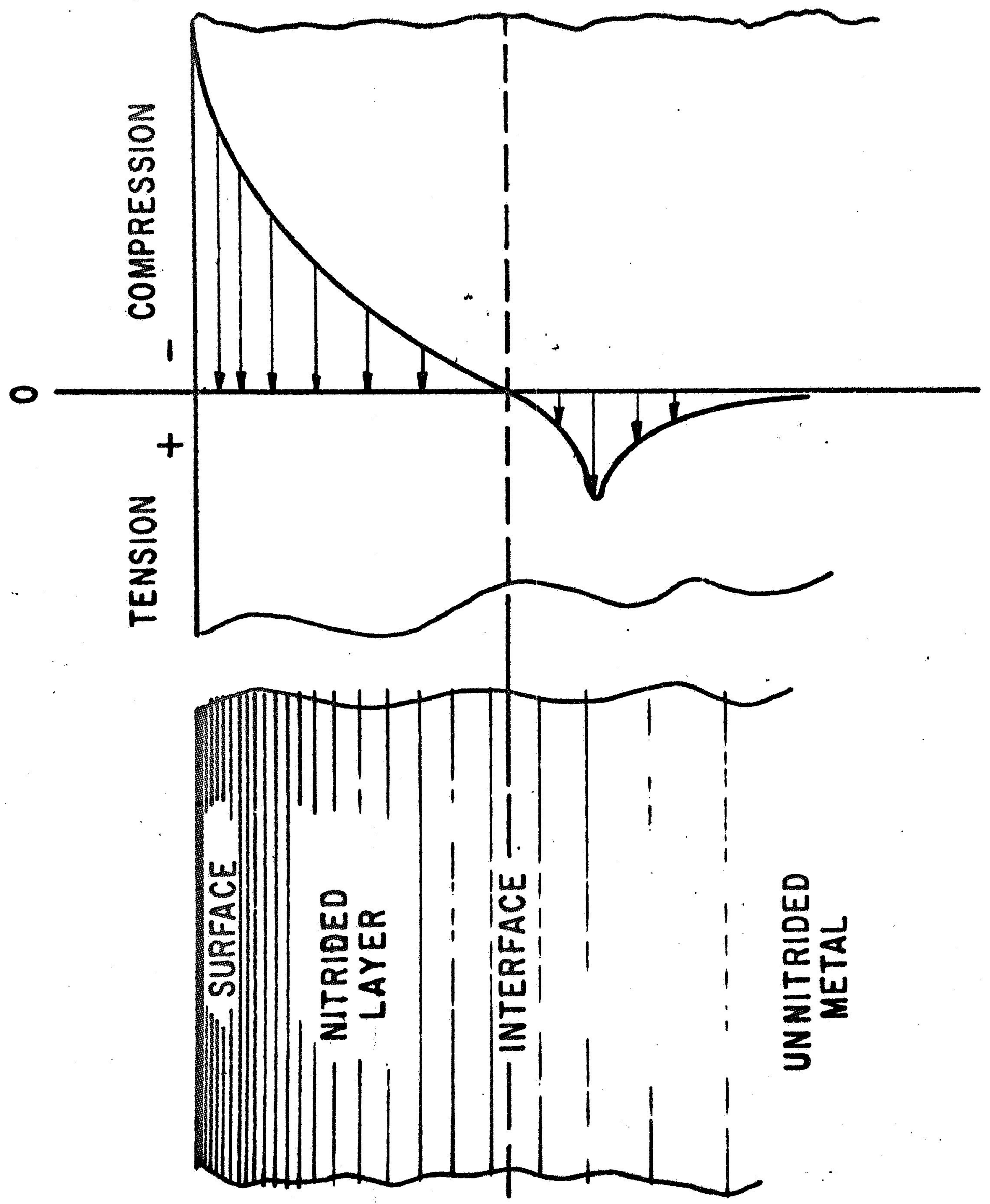




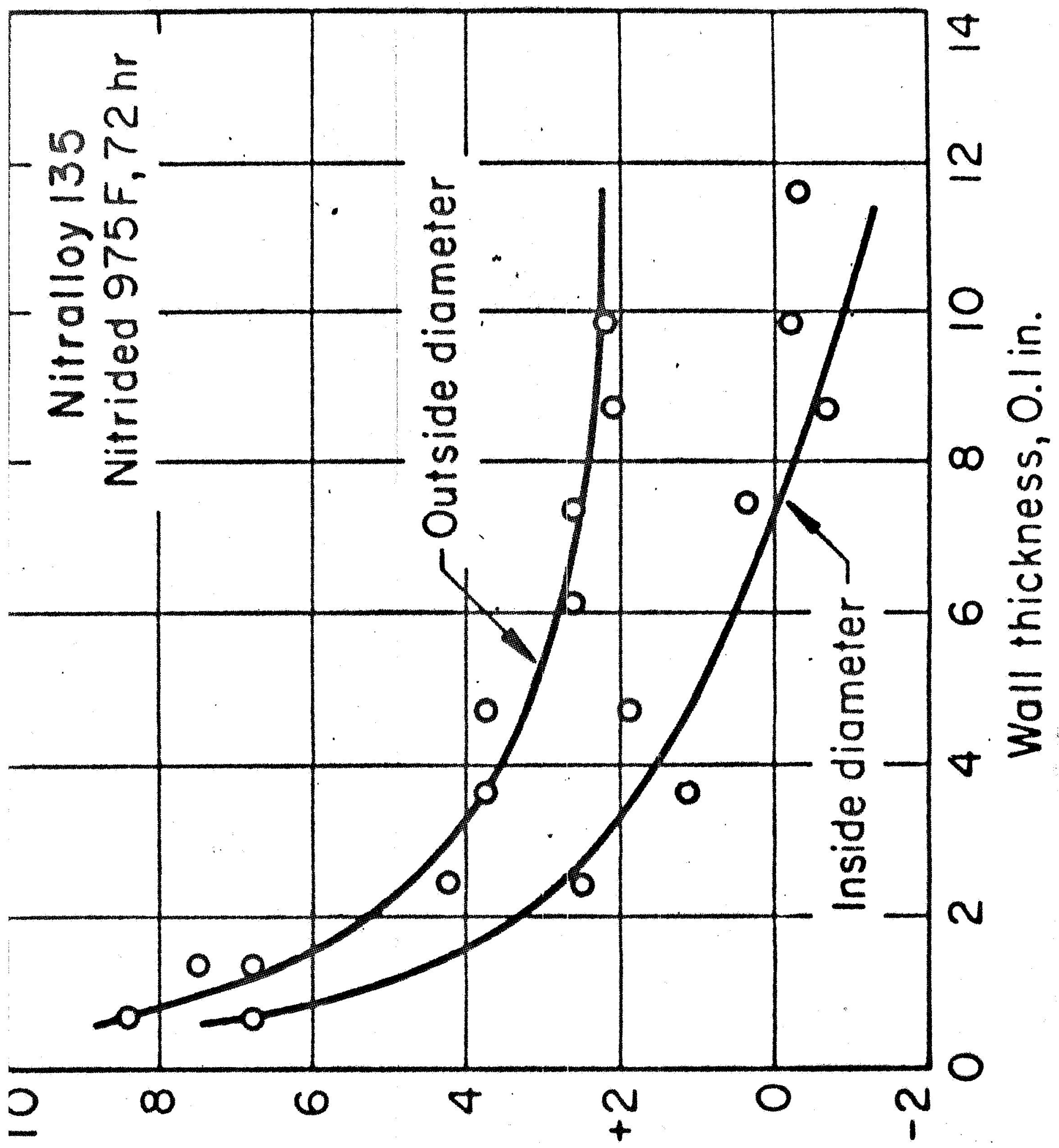

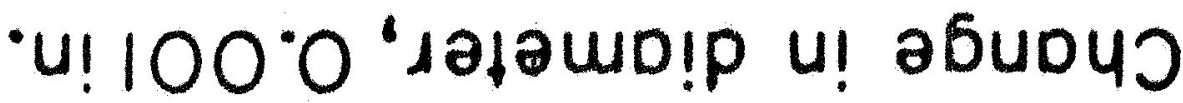





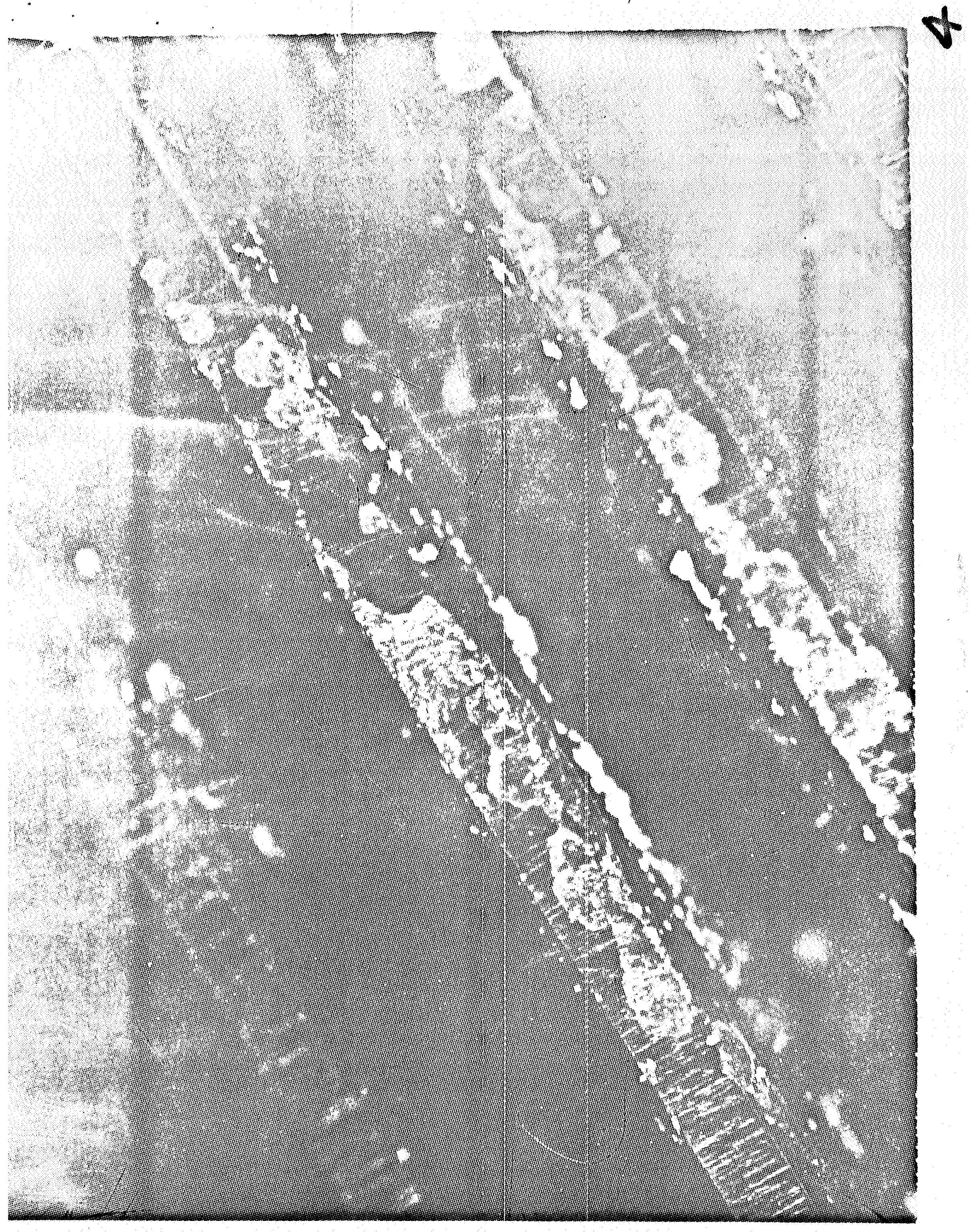




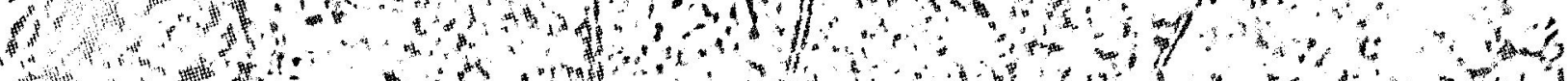

10

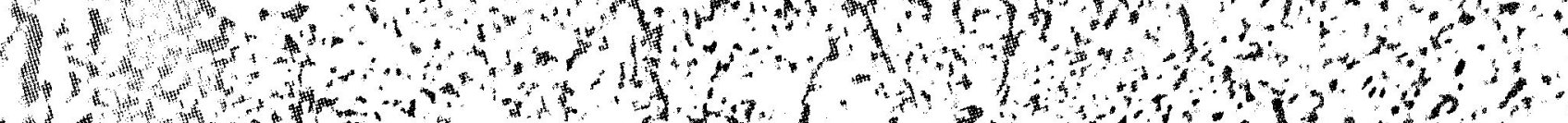

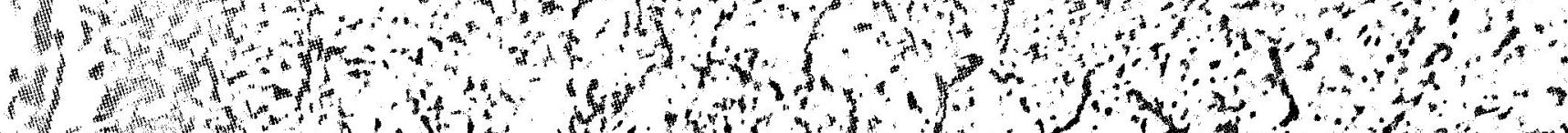

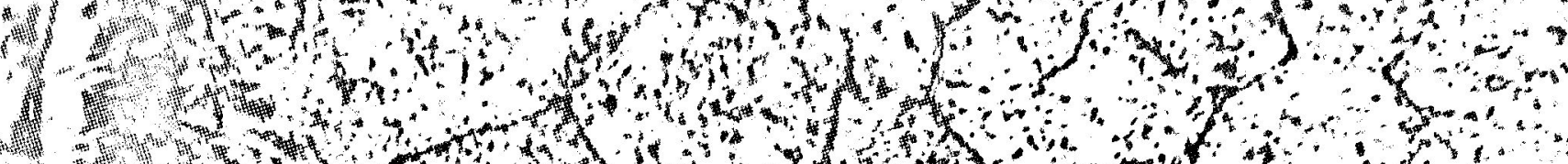
-

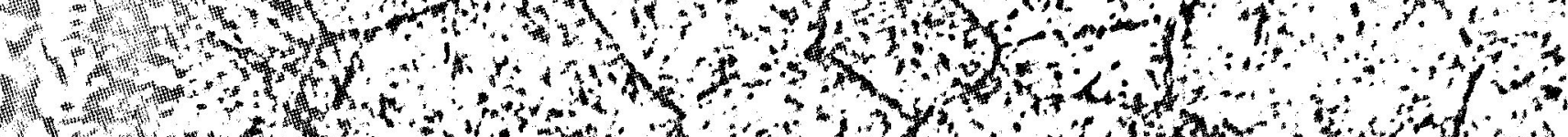
(1)

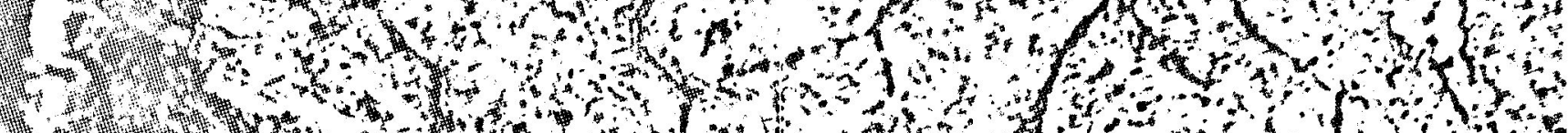
प1

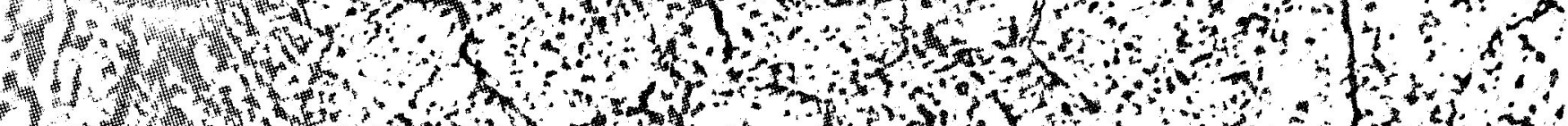
(1)

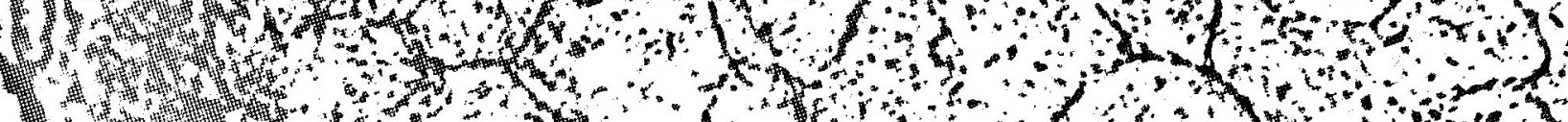

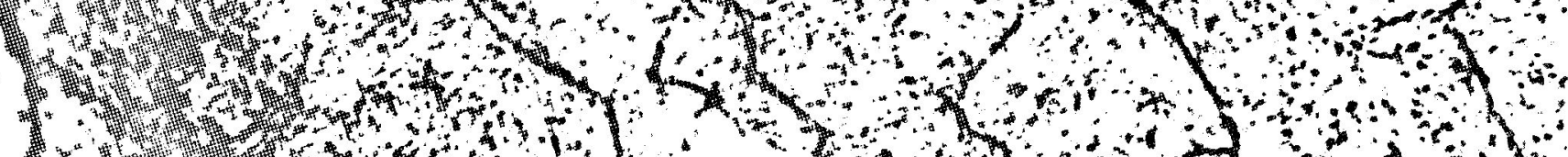
1) (1) (1) (1) (1) 20 (1)

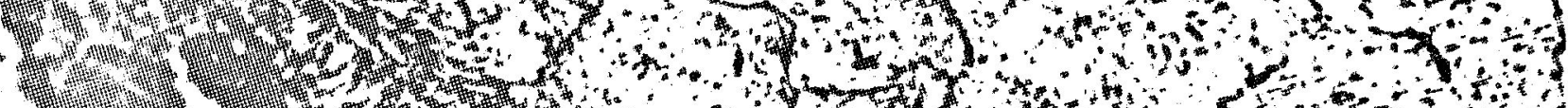

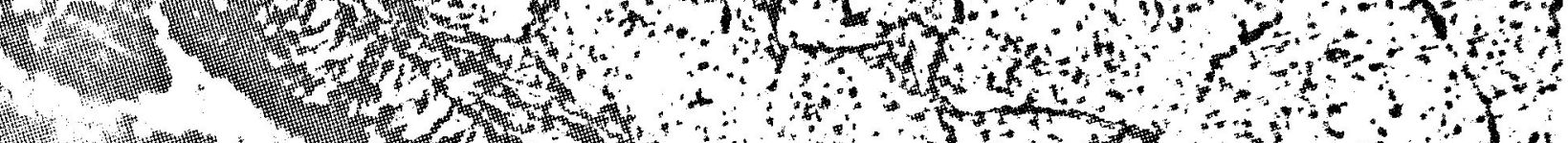

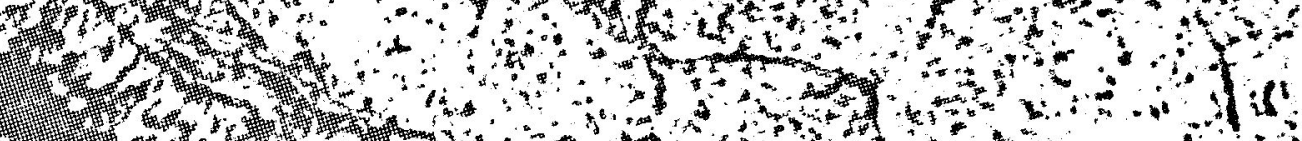
20 (1)

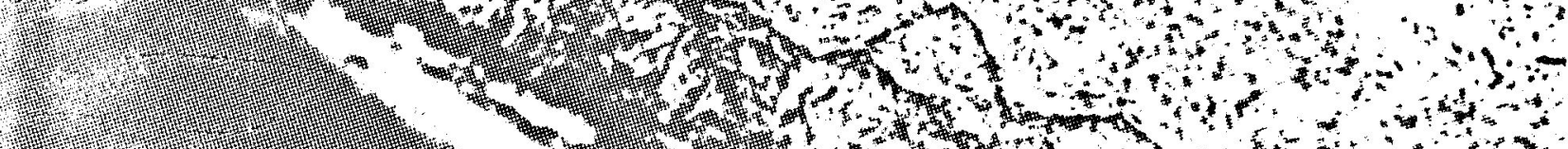

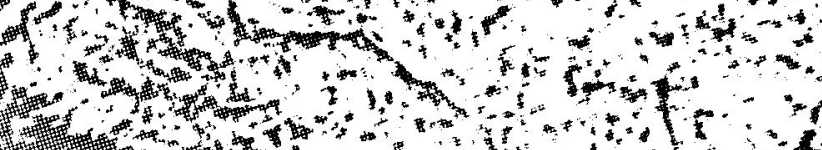

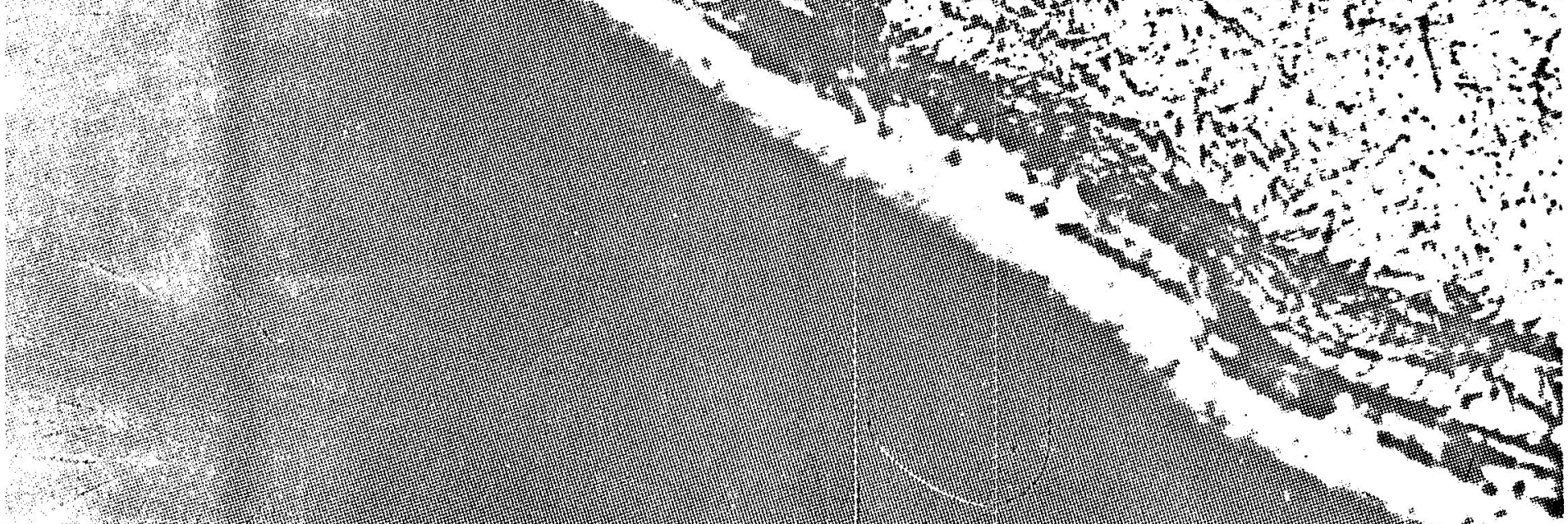




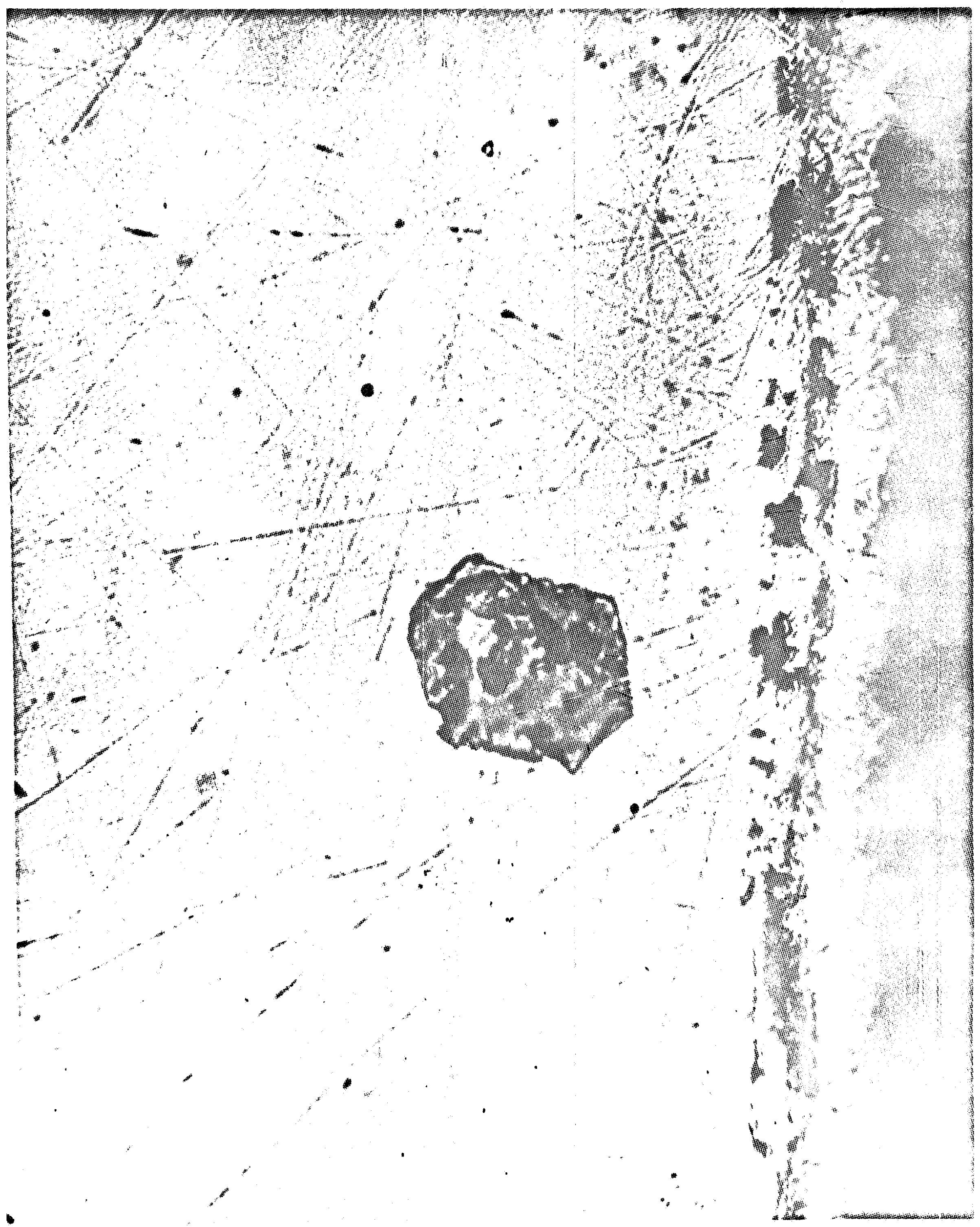




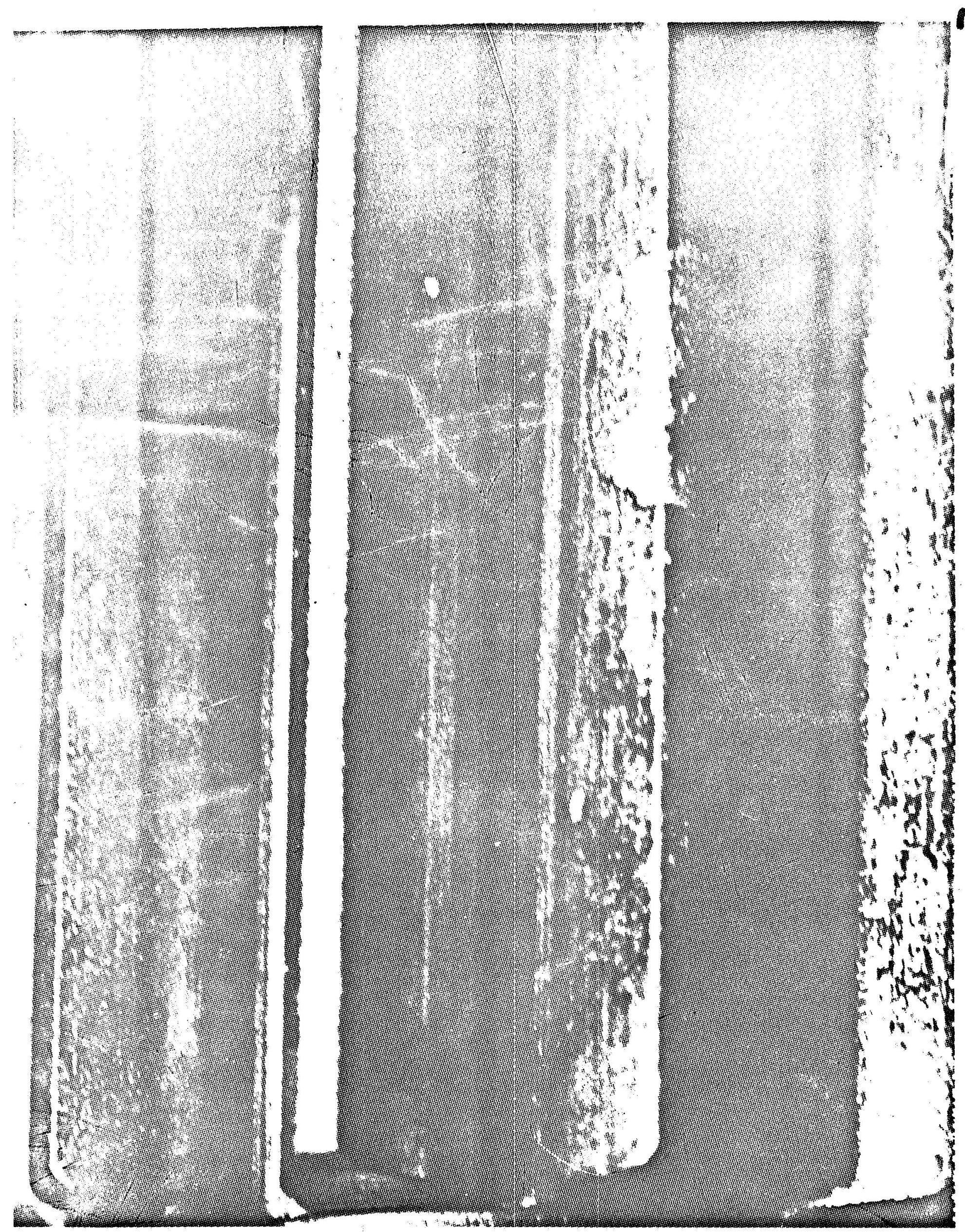




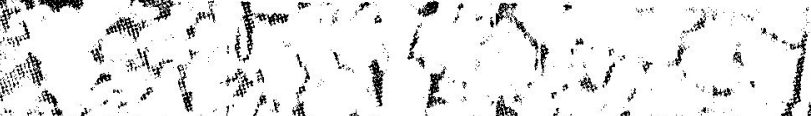

s.

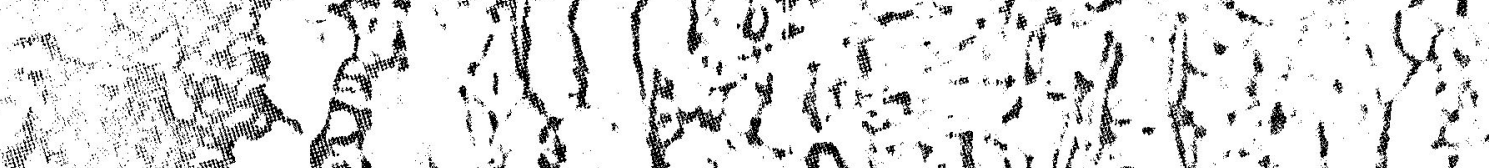

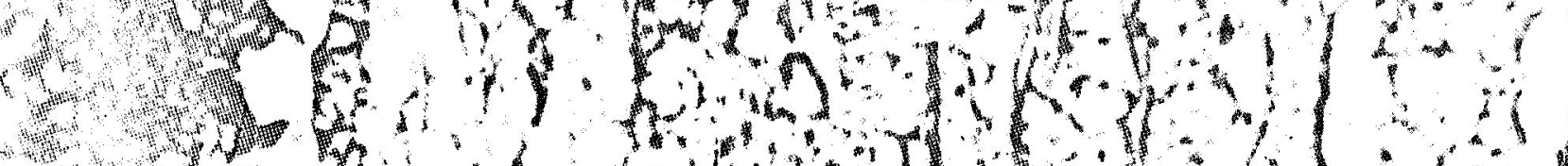

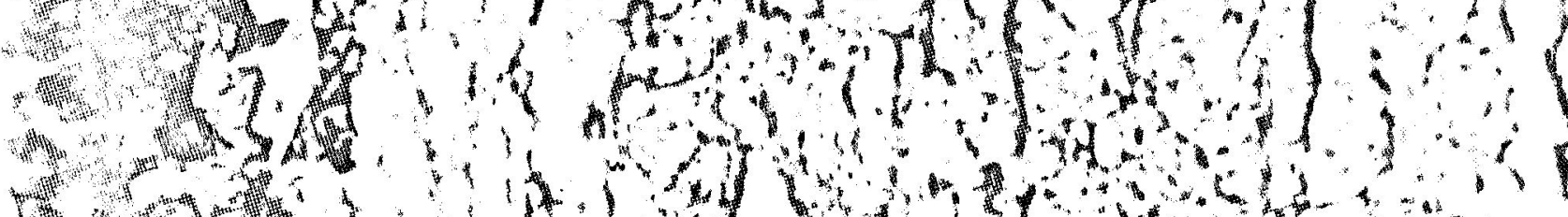

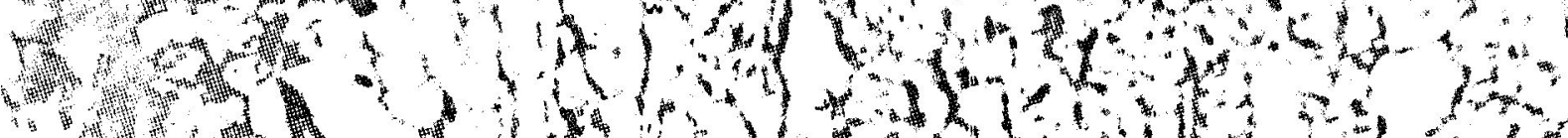

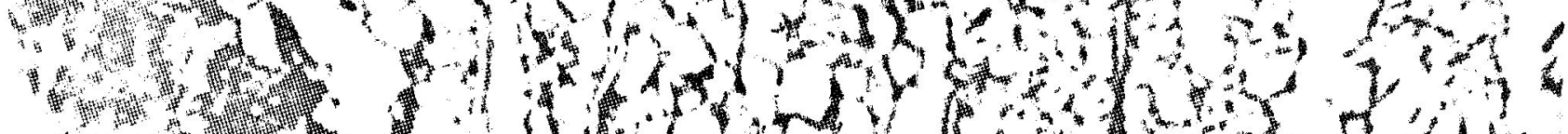

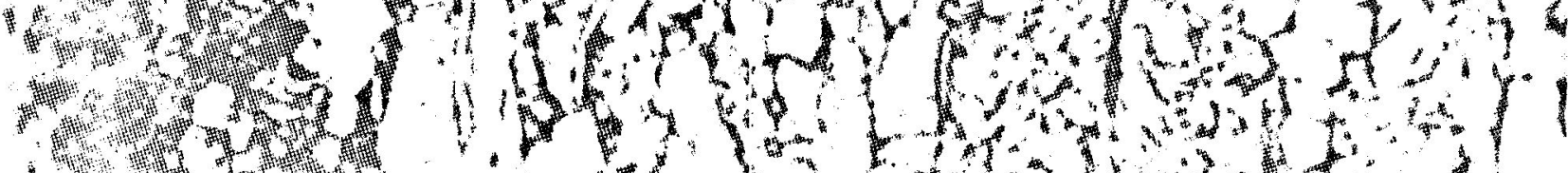

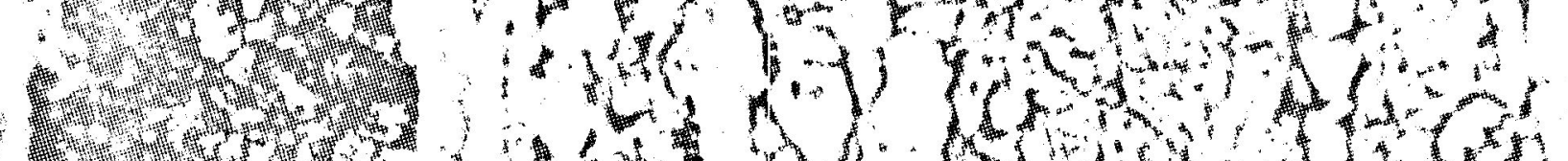

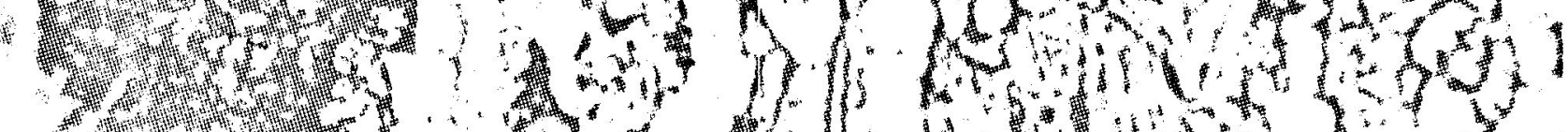

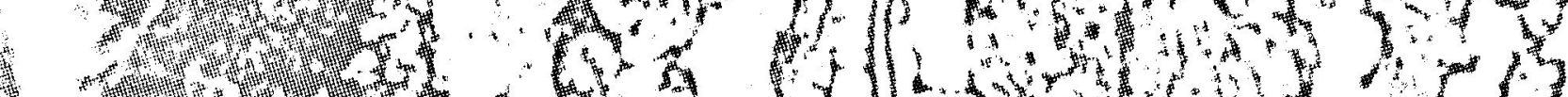
, the of

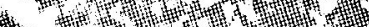

s.

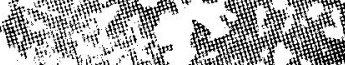

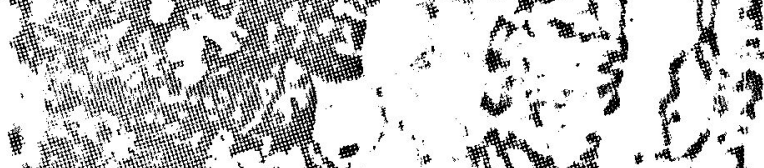
n. the $=3$

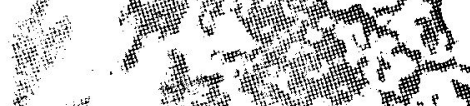

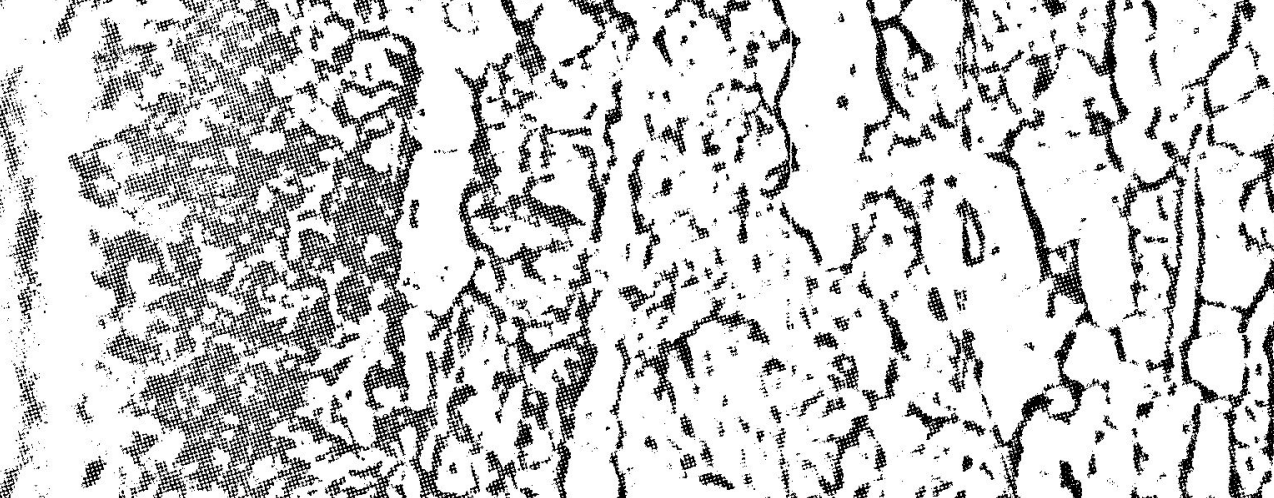
(3)

4)

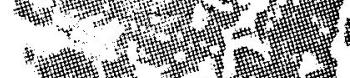

(1)

(2)

$\sqrt{1+1}$

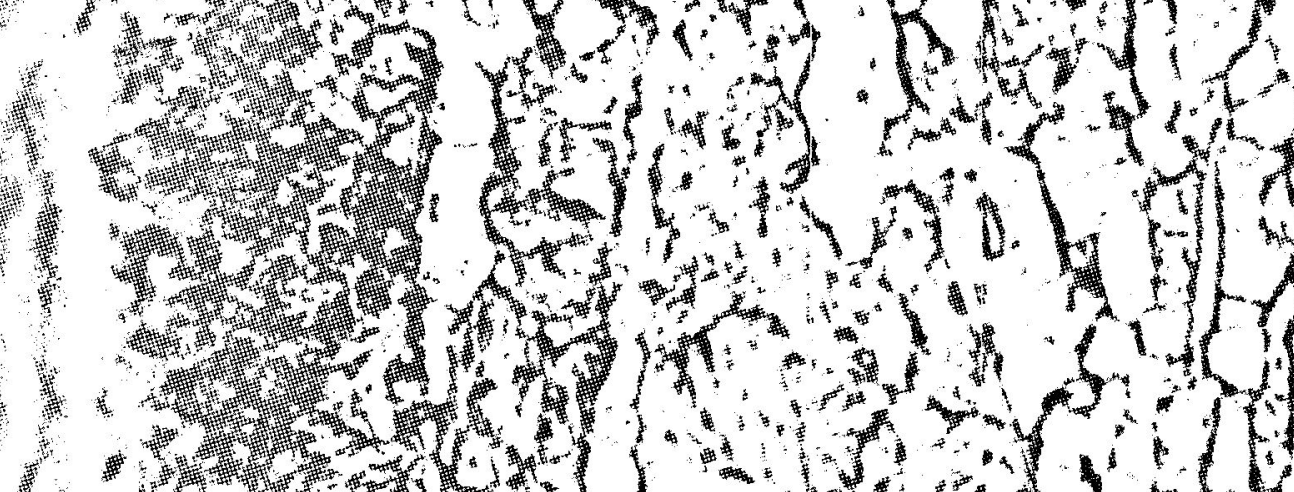
4 (1)

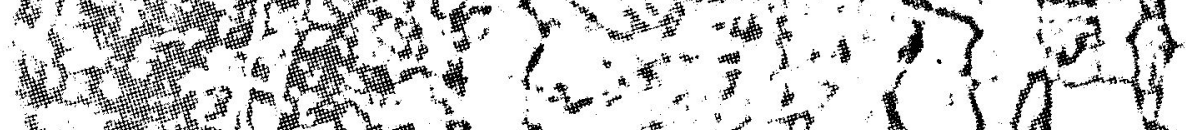
(4)

, 


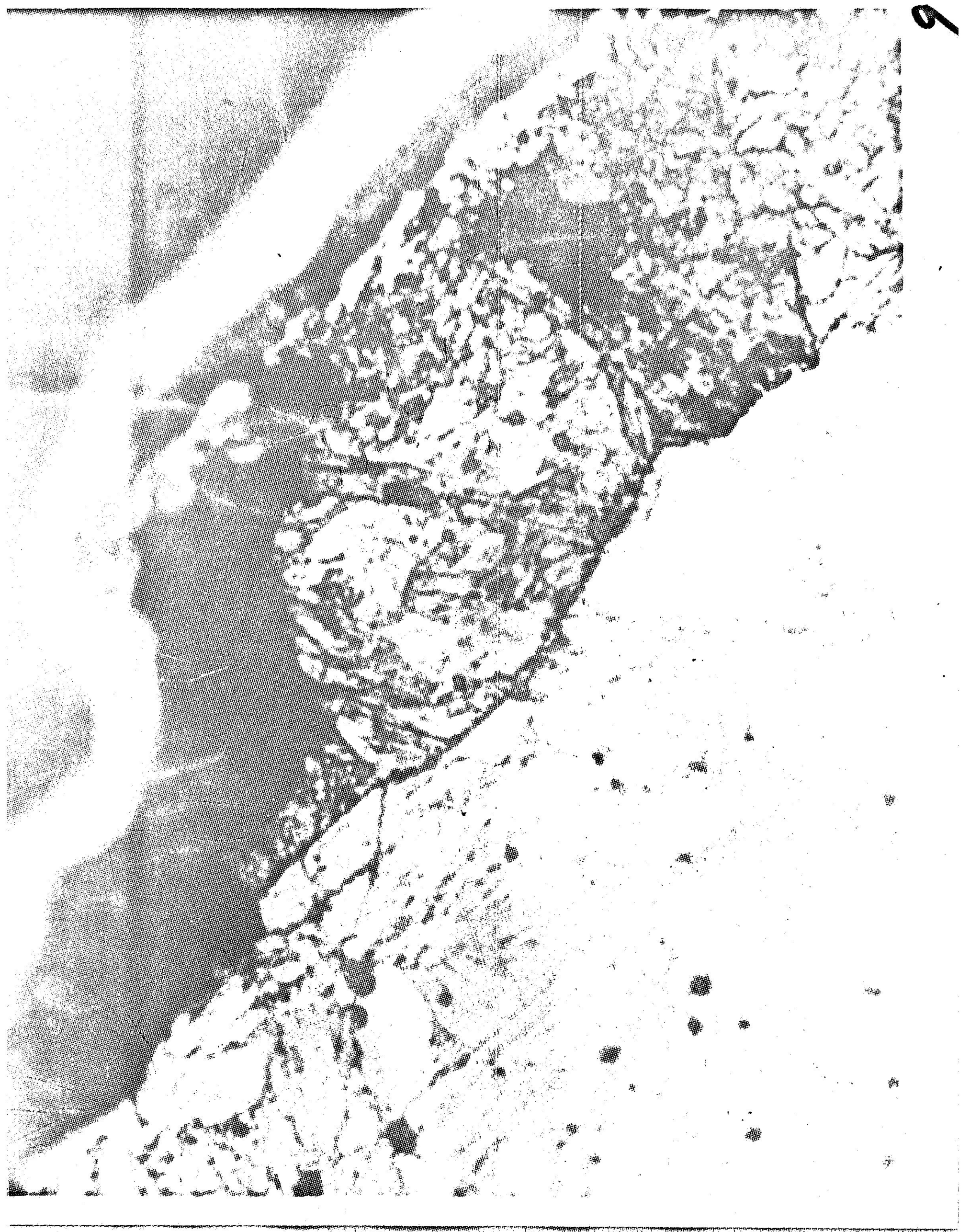



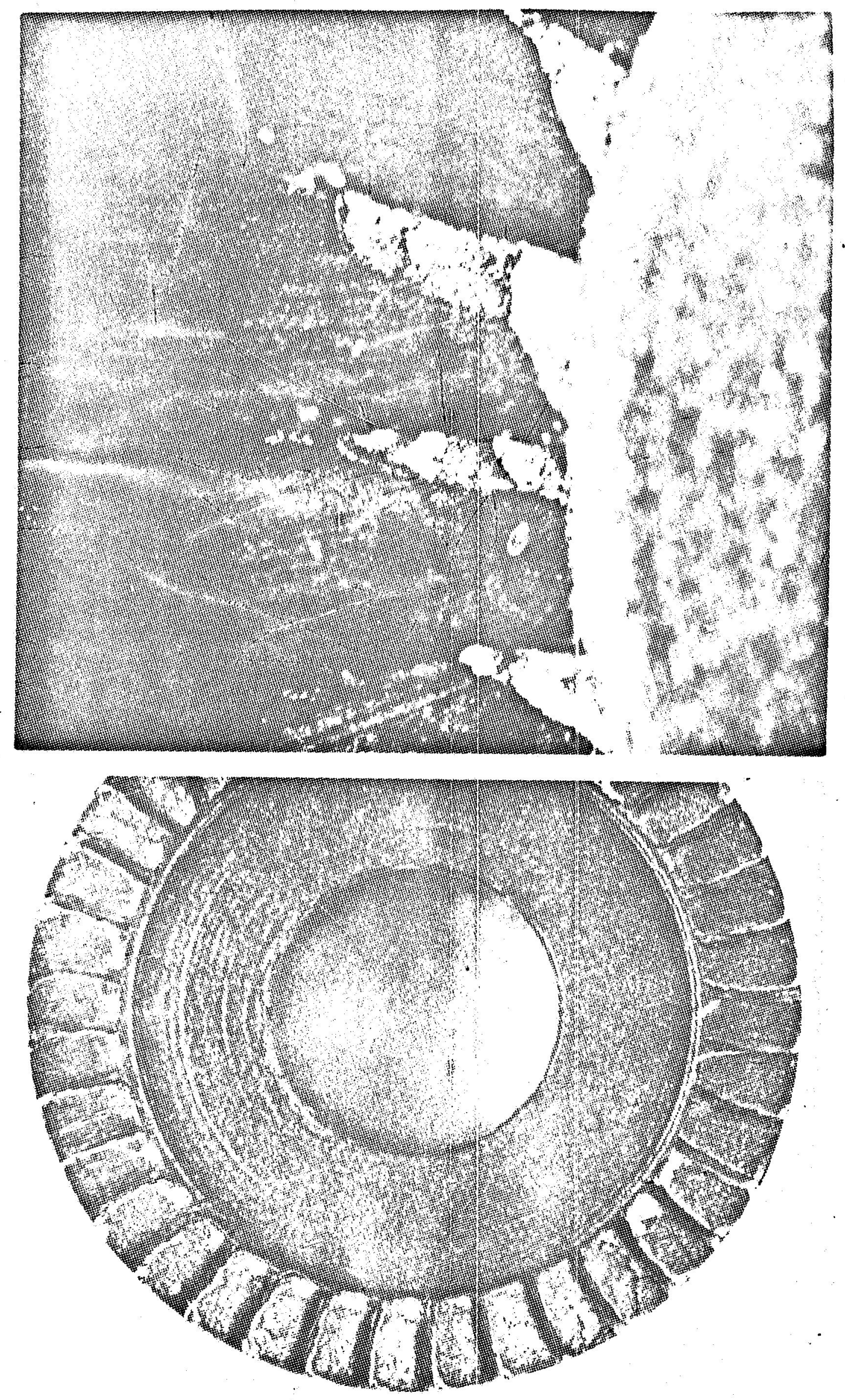

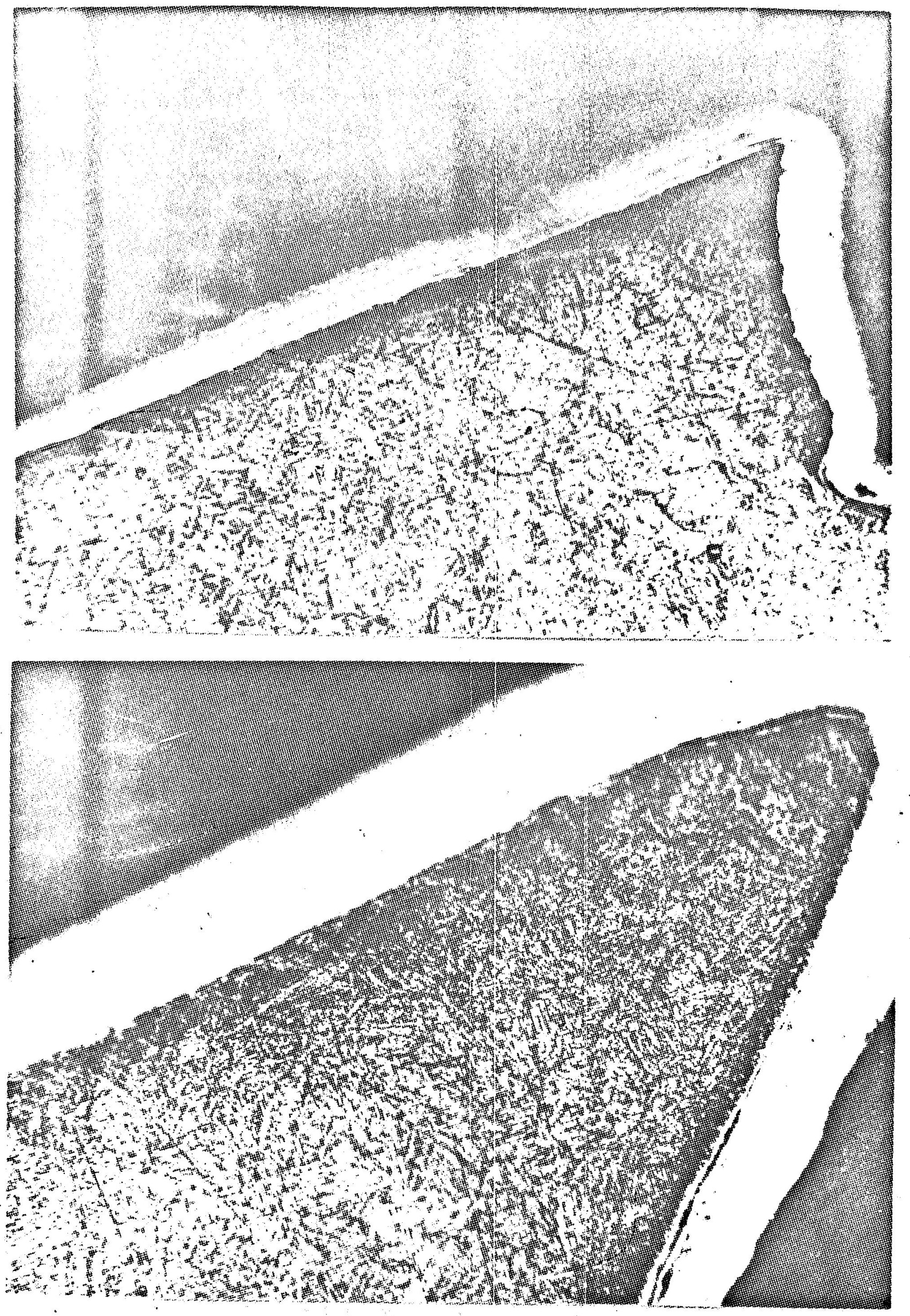